\title{
Correction to: An inverse approach to determine complex modulus gradient of field-aged asphalt mixtures
}

\author{
Meng Ling • Xue Luo $\cdot$ Fan Gu $\cdot$ Robert L. Lytton
}

Published online: 4 February 2019

(C) RILEM 2019

Correction to: Materials and Structures (2017) 50:138. https://doi.org/10.1617/s11527-017-1013-y

An inverse approach to determine complex modulus gradient of field-aged asphalt mixtures written by Meng Ling, Xue Luo, Fan Gu, Robert L. Lytton was originally published online without Open Access. After publication in volume 50, article ID 138 RILEM decided to grant the author to opt for open choice and to make the article an open-access publication. Therefore, the copyright of the article has been

The original article can be found online at https://doi.org/10.1617/s11527-017-1013-y.

M. Ling $(\bowtie)$

Texas A\&M Transportation Institute, CE/TTI Bldg 601C, 3135 TAMU, College Station, TX 77843-3135, USA

e-mail: mengling@tamu.edu

\section{Luo}

Texas A\&M Transportation Institute, CE/TTI Bldg 508B, 3135 TAMU, College Station, TX 77843-3135, USA

e-mail: xueluo@tamu.edu

F. Gu

National Center for Asphalt Technology, 277 Technology

Parkway, Auburn, AL 36830, USA

e-mail: fzg0014@auburn.edu

R. L. Lytton

Zachry Department of Civil Engineering, Texas A\&M

University, 3136 TAMU, College Station,

TX 77843-3136, USA

e-mail: r-lytton@ civil.tamu.edu changed to (C) The Author(s) 2018 and the article is forthwith distributed under the terms of the Creative Commons Attribution 4.0 International License (http://creativecommons.org/licenses/by/4.0/), which permits use, duplication, adaptation, distribution and reproduction in any medium or format, as long as you give appropriate credit to the original author(s) and the source, provide a link to the Creative Commons license and indicate if changes were made. 